\title{
Recurrent Small Gut Fecalomas Causing Obstruction- A Case Report
}

\author{
Mudassir Ahmad Khan ', Asif Mehraj ${ }^{2}$ Arshad Baba ${ }^{3}$, Mushtaq Laway ${ }^{3}$, Rauf A Wani ${ }^{2}$, \\ Fazl Q Parry ${ }^{2}$, Nisar A Chowdri ${ }^{2}$ \\ 'Department of General Surgery, GMC Rajouri \\ ${ }^{2}$ Department of General Surgery, Colorectal Surgery Division, SKIMS \\ ${ }^{3}$ Directorate of Health Services Kashmir
}

\section{A B S T R A C T}

\begin{abstract}
Fecaloma is a mass of hardened faeces difficult to pass through the intestinal lumen. Due to various reasons, a bolus of fecal matter stagnates, accumulates and inspisates in the intestinal lumen, until it becomes big enough to cause intestinal obstruction. Though there are various predisposing factors for the formation of fecaloma but the actual cause of fecaloma formation is still unknown. Small gut fecalomas are very rare. Herein we are presenting a case of 50 year male who underwent laparotomy three times for small gut obstruction caused due to recurrent formation of small gut fecaloma.

Keywords: Fecaloma; Small gut obstruction; Enterotomy; Laparotomy; Recurrent.

JMS: 2020; 23(3):30-32 DOI:https://doi.org/10.33883/jms.v23i3.763
\end{abstract}

\section{BACKGROUND}

First described by Abella ME in $1967^{1}$, fecaloma is a mass of hardened faeces difficult to pass through the intestinal lumen. Due to various reasons a bolus of fecal matter may stagnate and accumulate in the intestinal lumen, then it may get inspisated and gradually increase in size until the intestine may become obstructed. Fecaloma physically appears like a tumor ${ }^{2-3}$ on palpation of the gut intraoperatively. Fecaloma formation has been associated to various diseases like Hirschsprung's disease ${ }^{4}$, psychiatric patients, Chagas disease, spinal cord injuries, secondary to inflammatory and neoplastic diseases, and in chronic constipation ${ }^{5}$. Most of the impacted fecalomas have been reported in rectum and sigmoid ${ }^{6-7}$.Up till now only few cases of small gut fecaloma have been reported in the literature ${ }^{8.9}$. Herein we have a case to report of a patient who got operated many times for recurrent small gut fecaloma obstruction. To our knowledge it is the first case report of recurrent small gut fecaloma obstruction.

Case Description: This is an interesting case of a 50-year

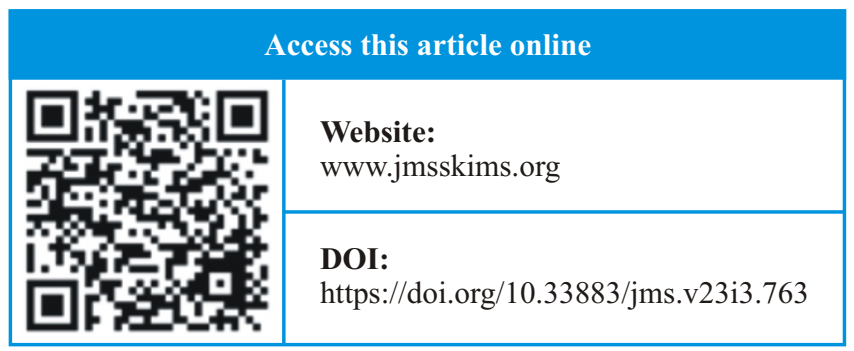

man with a surgically significant past history. About 20 years back the patient had undergone laparotomy with gastrojejunostomy with vagotomy for chronic duodenal ulcer and an emergency open appendectomy was done about 8 years ago. The patient was referred to our emergency room with abdominal pain, vomiting and abdominal distention for 3 days. Diagnosis of Intestinal obstruction was made and $\mathrm{E} / \mathrm{L}$ with enterotomy with removal of a large fecaloma ( $4 \times 8 \mathrm{~cm}$ large jejunal fecaloma; mixed with dead worms) at about $50 \mathrm{~cm}$ from DJ. Also large gut contained multiple small $(1 \times 1 \mathrm{~cm})$ fecalomas. Post-op period was uneventful and patient was discharged on 7 th POD.

Almost after one year, patient again got operated for small gut obstruction (Fig. 1) with E/L with adhesionolysis with

Correspondence:

Dr. Mudassir Ahmad Khan, MS

Assistant Professor, Department of General Surgery,

GMC Rajouri

Email:khanmudassir925@gmail.com

How to cite this article: Khan MA, Mehraj A, Baba A, Laway M, Wani RA, Parray FQ, Chowdhary NA. Recurrent Small Gut Fecalomas Causing Obstruction- A Case Report.JMS 2020; 23(3):30-32

Received: 2020-06-28 Accepted: 2020-08-11 


\section{Khan MA et al, Recurrent Small Gut Fecalomas Causing Obstruction- A Case Report}

enterotomy with removal of fecaloma. This time intraoperatively there were multiple dense adhesions between gut loops with moderate amount of inter-loop fluid, hard fecaloma impacted at about 3 feet proximal to ileo-Caecal valve, gut proximal to fecaloma dilated and edematous wall. Post-op period un-eventful and patient got discharged on 7th POD. After about two years of this second laparotomy for obstruction, patient again developed the features of small bowel obstruction which was initially managed conservatively as a case of SAIO but in view of recurrent episodes of SAIO the patient was ultimately managed by diagnostic lap followed by exploratory laparotomy with adhesionlysis with enterotomy with evacuation of multiple fecalomas with loop ileostomy. Intra-operatively dense adhesions involving small bowel were present with multiple fecalomas present in small bowel with dilatation of small gut proximal to the fecaloma impaction. Due to very dense adhesions the ileostomy loop could not be mobilized properly and we landed up in creation of proximal loop ileostomy that too not at a proper location and instead needed to be confectioned in the midline at supraumblical region in the main laparotomy wound (Fig. 2). Postoperatively the patient managed conservatively for fever with antibiotics and was discharged on 9th POD.

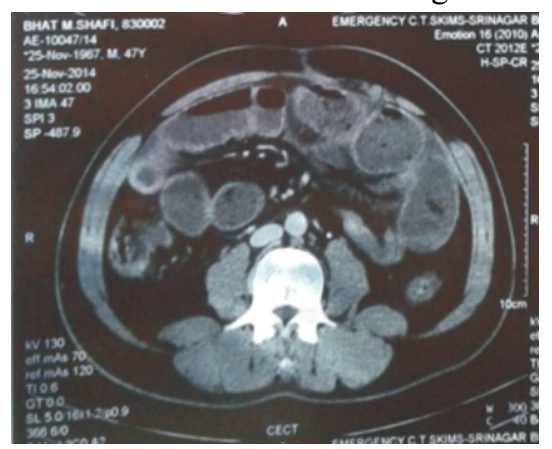

Fig. 1: CT picture of the patient showing features of small bowel obstruction.

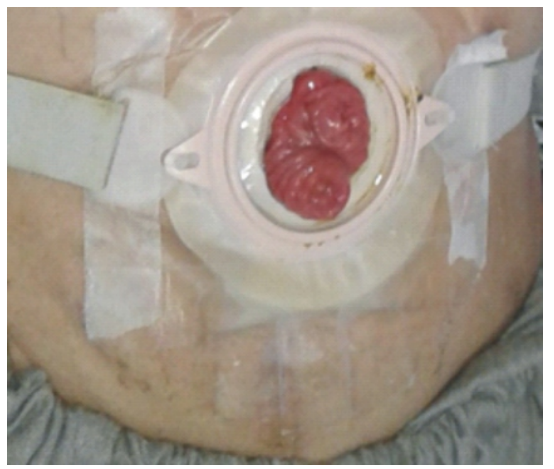

Fig. 2: Ileostomy in the midline at supraumblical region
Because of history of recurrent small gut fecalomaobstruction and before taking down the ileostomy we tried to find out any systemic cause for the formation of recurrent fecalomas in this patient. We did his thyroid profile, CFTR gene mutation (for adult onset cystic fibrosis) and CT enterography. However, all these tests were normal. Colonoscopy was done up to hepatic flexure that showed features of diversion colitis. Enteroscopy done via the stoma showed that the proximal jejunal loop was normal, distal ileal loop examined only up to $30 \mathrm{~cm}$ which was also normal (because the scope could not be advanced due to loop formation), conray injected through scope did not reveal any obstruction. Ultimately after about 6 months of last operation, the ileostomy was taken down unevent-fully and patient was put on low fibre diet with laxatives and till now patient is doing well.

\section{DISCUSSION}

Since only few cases of fecaloma causing small gut obstruction have been reported in literature, the exact incidence and prevalence of occurrence of small gut fecalomas is not known. Henceforth the treatment options are not standardized and vary with the factors like level of obstruction, condition of obstructed bowel and presence of co-morbidities. Stool softeners may be used by rectal route and even the digital rectal evacuation for recto-sigmoid fecalomas and oral mineral and olive oil usage are appropriate treatment methods for mild and moderate obstructions due to fecalomas ${ }^{10}$. However, when medical treatment is unsuccessful or when multiple impassable fecalomas are present or when the patient presents with features of acute obstruction, the surgical intervention becomes must. The recto-sigmoid is the most commonly involved area by fecalomas and the small bowel is a most unusual site ${ }^{11}$. This may be explained by the fact that stools in the left colon are firmer and have more solid consistency than those in other regions and also because the colon diameter is narrower on the left than the right $\mathrm{t}^{2 \mathrm{1} 12}$.

Coming to the discussion of our present case, the fecalomas developed recurrently in the small intestine landing the patient three times into emergency theatre for laparotomy and enterotomy and finally also the covering ileostomy. His thyroid profile, CFTR gene mutation, CT enterography, enteroscopy and colonoscopy were normal and apparently we could not find any cause for the formation of recurrent fecalomas in this patient. However the patient had a dietary 


\section{Khan MA et al, Recurrent Small Gut Fecalomas Causing Obstruction- A Case Report}

history of consuming excessive maize in his diet. Does any particular diet predisposes to fecaloma formation in the small intestine, is to be studied. Also the patient was a follow up case of laparotomy for duodenal ulcer treatment. Besides causing SAIO, does the post-operative adhesions predispose to the formation of small gut fecalomas is another query to be answered. The reason for 'troublecausing recurrent small gut fecaloma formation' in our patient still remains unanswered. However till now, the patient is doing well but God knows better when he will have adhesion or fecaloma obstruction again.

\section{CONCLUSION}

Only few cases of fecaloma causing small gut obstruction have been reported in literature, the exact incidence and prevalence of occurrence of small gut fecalomas is not known. Fecaloma formation may land the patient in trouble of getting operated in emergency settings for intestinal obstruction. The cause of recurrent formation of small gut fecalomas remains unknown. Our case needed to be operated three times for recurrent fecaloma obstruction and fourth time for ileostomy take-down.

Clinical Significance: Fecaloma formation may land the patient in trouble of getting operated in emergency for intestinal obstruction. The actual cause for recurrent formation of small gut fecalomas remained unknown.

Acknowledgment: For managing this case very efficiently, we acknowledge the support rendered by the resident doctors and the nursing staff especially the Stoma Care Nurses of the Colorectal Division of the Department of General Surgery SKIMS, Soura Srinagar.

Conflict of Interest: Authors declare that they have no conflict of interest.

Funding declaration: No funding was received in preparation of this manuscript.

\section{REFERENCES}

1) Abella ME, Fernández AT. Large fecalomas. Dis Colon Rectum. 1967;10(5):401-4.

2) Yucel AF, Akdogan RA, Gucer H. A giant abdominal mass: fecaloma. Clin Gastroenterol Hepatol. 2012;10(2):e9-e10.
3) Zurabishvili K, Rekhviashvili A, Sakhamberidze M, Tsiklauri K. A case of giant fecaloma in a 24-yearold woman. Georgian Med News. 2015(240):11-4.

4) Campbell JB, Robinson AE. Hirschsprung's disease presenting as calcified fecaloma. Pediatr Radiol. 1973;1(3):161-3.

5) Caiazzo P, De Martino C, Del Vecchio G, Di Lascio P, Marasco M, Laviani F, et al. Megacolon for a giant faecaloma with unlucky outcome: case report and review of the literature. Ann Ital Chir. 2013;84(3):31922.

6) Rajagopal A, Martin J. Giant fecaloma with idiopathic sigmoid megacolon: report of a case and review of the literature. Dis Colon Rectum. 2002;45(6):833-5..

7) Zimmers T. Giant calcified fecaloma. Ann Emerg Med. 1984;13(9 Pt 1):749.

8) Mushtaq M, Shah MA, Malik AA, Wani KA, Thakur N, Parray FQ. Giant Fecaloma Causing Small Bowel Obstruction: Case Report and Review of the Literature. Bull Emerg Trauma. 2015;3(2):70-72.doi: 10.7508/beat.2015.02.007.

9). Ha Yeong Yoo, Hye Won Park, Seong-Hwan Chang and Sun Hwan Bae. Ileal Fecaloma Presenting with Small Bowel Obstruction. Pediatr Gastroenterol Hepatol Nutr 2015 September 18(3):193-196. pISSN: 22348646 e I S S N : $\quad 2234-8840$ http://dx.doi.org/10.5223/pghn.2015.18.3.193

10) Aykut Soyder, Hedef Özgün. Giant Fecaloma in a 16Year-Old Boy: Case Report. Kolon Rektum Hast Derg 2012;22:160-163

11). Cid AA, Pietruk T, Bidari CZ, Ehrinpreis MN. Cecal fecaloma mimicking colonic neoplasm. Dig Dis Sci. 1981;26:1134-7.

12). Sakai E, Inokuchi $Y$, Inamori $M$, Uchiyama $T$, Iida $H$, Takahashi H, et al. Rectal fecaloma: successful treatment using endoscopic removal. Digestion 2007;75:198. 